\title{
Smoke aerosol and its radiative effects during extreme fire event over Central Russia in summer 2010
}

\author{
N. Chubarova ${ }^{1}$, Ye. Nezval'1, I. Sviridenkov ${ }^{2}$, A. Smirnov ${ }^{3}$, and I. Slutsker ${ }^{3}$ \\ ${ }^{1}$ Faculty of Geography, Moscow State University, 119991, Russia \\ ${ }^{2}$ A.M. Obukhov Institute of Atmospheric Physics RAS, Moscow, 119017, Russia \\ ${ }^{3}$ Sigma Space Corporation, code 614.4, NASA/Goddard Space Flight Center, Greenbelt, MD 20771, USA \\ Correspondence to: N. Chubarova (chubarova@imp.kiae.ru)
}

Received: 26 September 2011 - Published in Atmos. Meas. Tech. Discuss.: 13 October 2011

Revised: 4 January 2012 - Accepted: 23 January 2012 - Published: 9 March 2012

\begin{abstract}
Different microphysical, optical and radiative properties of aerosol were analyzed during the severe fires in summer 2010 over Central Russia using ground measurements at two AERONET sites in Moscow (Meteorological Observatory of Moscow State University - MSU MO) and Zvenigorod (Moscow Region) and radiative measurements at the MSU MO. Volume aerosol size distribution in smoke conditions had a bimodal character with the significant prevalence of fine mode particles, for which effective radius was shifted to higher values $\left(r_{\text {eff-fine }}=0.24 \mu \mathrm{m}\right.$ against approximately $0.15 \mu \mathrm{m}$ in typical conditions). For smoke aerosol, the imaginary part of refractive index (REFI) in the visible spectral region was lower than that for typical aerosol $\left(\operatorname{REFI}_{\lambda}=675 \mathrm{~nm}=0.006\right.$ against $\left.\operatorname{REFI}_{\lambda}=675 \mathrm{~nm}=0.01\right)$, while single scattering albedo (SSA) was significantly higher $\left(\mathrm{SSA}_{\lambda=675 \mathrm{~nm}}=0.95\right.$ against $\left.\mathrm{SSA}_{\lambda=675 \mathrm{~nm}} \sim 0.9\right)$. Extremely high aerosol optical thickness at $500 \mathrm{~nm}$ (AOT500) was observed on 6-8 August reaching the absolute maximum on 7 August in Moscow (AOT500 =6.4) and at Zvenigorod $($ AOT500 $=5.9)$. A dramatic attenuation of solar irradiance at ground was also recorded. Maximum irradiance loss had reached $64 \%$ for global shortwave irradiance, $91 \%$ for UV radiation $300-380 \mathrm{~nm}$, and $97 \%$ for erythemally-weighted UV irradiance at relatively high solar elevation $47^{\circ}$. Significant spectral dependence in attenuation of solar irradiance in smoky conditions was mainly explained by higher AOT and smaller SSA in UV (0.8-0.9) compared with SSA in the visible region of spectrum. The assessments of radiative forcing effect (RFE) at the TOA indicated a significant cooling of the smoky atmosphere. Instant RFE reached $-167 \mathrm{Wm}^{-2}$ at AOT500 $=6.4$, climatological RFE calculated with August 2010 monthly mean AOT was about $-65 \mathrm{Wm}^{-2}$, compared with $-20 \mathrm{Wm}^{-2}$ for typical aerosol according to the $10 \mathrm{yr}$ period of measurements in Moscow.
\end{abstract}

\section{Introduction}

Unprecedented hot and dry weather in summer 2010 caused intensive forest and peatbog fires over the vast territory of Central Russia. These conditions significantly changed the atmospheric gas composition, optical and radiative characteristics of aerosol, and, as a result, solar irradiance at the top and at the bottom of the atmosphere, which in turn imposed feedback effects on regional conditions of the climate system. High aerosol concentration caused detrimental influence on human health, and the mortality rate increased by 1.5-1.6 times over this period (Materials of All-Russian conference, 2010).

This paper is devoted to the analysis of aerosol properties and radiative effects during the 2010 fire event and to the comparisons of smoke aerosol with typical characteristics of the atmosphere over the Moscow area. In addition, the comparisons were made with the results obtained during the 2002 fire event in Central Russia described in Chubarova et al. (2009), Gorchakov et al. (2004), and Tarasova et al. (2004), as well as during other wildfire conditions in different parts of the world (Dubovik et al., 2002; Eck et al., 2003).

The aerosol database used in this study includes the data from the two AERONET sites (MSU MO and Zvenigorod) located at some distance from the main sources of smoke aerosol. Accurate multi-channel measurements by CIMEL sun/sky photometer through UV to near-infrared spectral region provided the data for evaluating a spectral dependence of aerosol optical thickness as well as many other inversion products, including size distribution, effective radius, aerosol phase function, refractive index, single scattering albedo, asymmetry factor, etc. (Dubovik and King, 2000). 
In order to study radiative effects of smoke aerosol, we examined the attenuation of solar irradiance at ground in several broadband spectral ranges, including UV spectral region, using the data of the Meteorological Observatory of Moscow State University (http://momsu.ru/english.html). To assess the radiative effects of aerosol on solar irradiance, radiative transfer modelling was applied. Using the AERONET inversion products, we also estimated aerosol radiative forcing effects at the top of the atmosphere during fire events and compared them with the results in typical conditions.

\section{Data and methods of the analysis}

The analysis was fulfilled using data of two collocated AERONET CIMEL sun/sky photometers: one located at the Moscow State University Meteorological Observatory (MSU MO) $\left(55.7^{\circ} \mathrm{N}, 37.5^{\circ} \mathrm{E}\right)$ and one at the Zvenigorod Scientific Station (ZSS) of the A.M. Obukhov Institute of Atmospheric Physics $\left(55.7^{\circ} \mathrm{N}, 36.8^{\circ}\right.$ E). The approximate distance between the sites is about $55 \mathrm{~km}$ and the time difference between measurements is only $3 \mathrm{~min}$. Direct Sun measurements are made with $1.2^{\circ}$ full field of view collimator at $340,380,440,500,675,870,940$ and $1020 \mathrm{~nm}$ in a sequence of 3 measurements (termed a triplet) taken $30 \mathrm{~s}$ apart at each wavelength every 15 min during daytime and at precomputed optical airmass values during morning and afternoon (Holben et al., 1998, 2001). CIMEL instrument at Zvenigorod site has an additional $1640 \mathrm{~nm}$ channel.

Measurements in solar almucantar and in solar principal plane are made in four channels: 440, 670, 870 and $1020 \mathrm{~nm}$ in Moscow and in six channels (additional are 500 and $1640 \mathrm{~nm}$ ) at Zvenigorod site every hour during daytime and at certain solar zenith angles in morning and evening conditions. The direct Sun measurements are used to compute aerosol optical thickness (AOT) at different wavelengths except that for $940 \mathrm{~nm}$ channel, which is used to estimate the total water vapor content $W$. The uncertainty of AOT measurements does not exceed 0.01 in visible range and 0.02 in UV spectral range (Eck et al., 1999), which is currently one of the best achieved accuracy of AOT measurements.

Both direct and diffuse AERONET measurements are used in an inversion algorithm developed by Dubovik and King (2000). This algorithm provides improved aerosol retrievals by fitting the entire measured field of radiances - sun radiance and the angular distribution of sky radiances - at four wavelengths $(440,670,870$ and $1020 \mathrm{~nm})$ to a radiative transfer model. As a result, different microphysical, optical and radiative aerosol properties in the total atmospheric column can be estimated (i.e. aerosol refractive index, single scattering albedo, volume size distribution in the size range of $0.05 \mu \mathrm{m} \leq r \leq 15 \mu \mathrm{m}$, volume concentration, effective radius, etc). Version 2.0 quality assurance criteria were utilized in the analysis (Holben et al., 2006).

Depending on their quality, the AERONET data also correspond to different levels. All real-time measurements are assigned to the level 1. Since the instrument is automatically operated, a special automated algorithm of cloud-screening has been developed (Smirnov et al., 2000). The data, which successfully pass the procedure of cloud screening, are assigned to the level 1.5. After the final calibration and some additional checks, the data are assigned to the final level 2.0. One hour visual cloud observations at the MSU MO provide additional useful information on possible cloud contamination. Some additional criteria based on cloud data has been developed (Uliumdzhieva et al., 2005). This additional filter allows us to improve significantly the quality of the aerosol climatology by eliminating the cases with thin homogeneous cirrus clouds, which are very hard to exclude automatically using the standard cloud screening procedure. After the final calibration the data at all levels are assigned to the ultimate calibration status.

In this analysis, special processing was used for the day 7 August 2010 with extremely high AOT for Moscow and Zvenigorod datasets. The AOT values were computed from the raw voltages using individual measurements within a triplet, since limits on triplet variation in the AERONET algorithm even at level 1 have led to removing the data with strong changes. Such variations within triplet can occur in conditions with extremely high aerosol loading. Though these data are not the standard AERONET product, they will be useful in the analysis, since they show real AOT level observed in smoky conditions.

Unfortunately, there were some additional problems with the Zvenigorod CIMEL instrument associated with the obstruction in the collimator, starting in the beginning of June 2010. So, the measured AOTs were higher and sky radiances were lower than the actual values. In order to recover the data of measurements during smoke episodes, a correction procedure based on the independence on average of the AOT from the solar zenith angle in conditions with low atmospheric turbidity was applied to the data. Such an approach to the sunphotometer calibration was described in (Korotaev et al., 1993) and can be used when it is not possible to apply the Langley plot method. This approach was realized in the following way. For July-August period, 2010 we selected the days which were not affected by smoke aerosol. Then, the correction coefficients for the extraterrestrial instrumental constants were collated manually by using the criterion of the independence ofn average of the AOT on solar zenith angle for short periods (about one hour) at sunrise and sunset. Additionally, in some specific cases, data of parallel measurements in Moscow were used to check the stability of aerosol content. This updated calibration was applied to the raw data for the June-October time period for the Zvenigorod dataset. This approach significantly improved the quality of data. It should be noted that the applied method differs from the standard AERONET algorithm. However, the application of the special processing resulted in an excellent matching with the inversion products at Moscow (MSU MO) site at the AERONET level 2.0 (for example, single scattering 
albedo) for the same period of measurements that indirectly approved the reliability of this approach.

The aerosol properties in smoky aerosol conditions were compared with the averages for $10 \mathrm{yr}$ period of continuous measurements at the Moscow MSU MO site (2001-2010). These average aerosol characteristics we termed as typical characteristics of aerosol over Moscow.

In addition, we used MSU MO radiative measurements of global shortwave irradiance (300-4500 nm), UV irradiance $300-380 \mathrm{~nm}$ with the effective wavelength at $340 \mathrm{~nm}$, and erythemally-weighted (EW) irradiance with the maximum sensitivity in UV-B region $(\lambda<315 \mathrm{~nm}$ ) (Chubarova and Nezval', 2000; Nezval' and Chubarova, 2007; Chubarova, 2008). The UV instruments (UV-A YES pyranometer, and UV-B YES pyranometer) are regularly calibrated against the ultraviolet spectroradiometer Bentham DTM300 of the Medical University of Innsbruck (courtesy of M. Blumthaler). The correction on total ozone and solar zenith angle for the UV-B YES pyranometer data was applied in order to minimize the errors at high solar zenith angles and large ozone content in accordance with recommendations described in (Seckmeyer et al., 2006). The shortwave irradiance is obtained by standard Russian instruments as a sum of direct irradiance on the horizontal surface and diffuse irradiance. These instruments are calibrated against Russian reference instruments, which in turn are tested in Davos (Switzerland) according to the WMO standards.

Radiative measurements were made with one minute resolution. All the data were hourly averaged to make the datasets more uniform and comparable with the AERONET inversion products, which have one hour resolution. We analyzed the changes of solar irradiance in terms of losses $(L$, $\%)$. They were estimated against model calculations of solar irradiance in the aerosol-free atmosphere according to the Monte Carlo RT code developed in IMP RRC "Kurchatov Institute" (http://litms.molnet.ru/csif/index.php) for shortwave irradiance $300-4500 \mathrm{~nm}$ and according to the TUV model (Madronich and Flocke, 1998) with 8-stream discrete ordinate RT code for UV irradiance.

Using the TUV model, we also made the comparisons between model and measured irradiance in UV spectrum in smoke aerosol conditions. For global shortwave irradiance (300-4500 nm), similar comparisons were performed with the help of the AERONET RT model (Garcia et al., 2008), which is also based on discrete ordinate RT code. For this purpose, one minute resolution data were taken to match the exact time of AERONET AOT observations and the model dataset.

It should be emphasized that all data marked as "Moscow" in the paper refer to the measurements provided by Meteorological Observatory of Moscow State University (MSU MO).

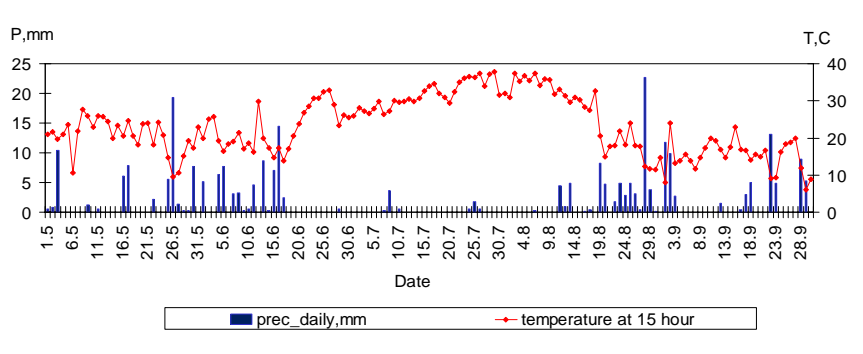

Fig. 1. Air temperature $T\left({ }^{\circ} \mathrm{C}\right)$ at 15:00 local time and daily precipitation $P(\mathrm{~mm})$ during warm May-September period 2010 in Moscow according to the data of Meteorological Observatory of Moscow State University.

\section{Results}

\subsection{Meteorological conditions and temporal variation of aerosol}

Weather conditions in summer 2010 were characterized by unprecedented duration of anticyclone blocking (more than 50 days), which led to the stable advection of hot dry air mainly from the south-eastern direction - from the heart of the continent. This resulted in a significant increase of air temperatures to the absolute maxima over the whole period of the instrumental observations and in the near absence of precipitation. Figure 1 presents the data series of temperature and daily precipitation during warm period 2010 in Moscow. Since July the daily mean temperature exceeded $25^{\circ} \mathrm{C}$ and in some days $-30^{\circ} \mathrm{C}$. On 29 July, the absolute temperature maximum of $38.1{ }^{\circ} \mathrm{C}$ was recorded. The temperature anomaly in July was about $+8{ }^{\circ} \mathrm{C}$ and about $6{ }^{\circ} \mathrm{C}$ in August. The total precipitation during the whole month of July and the first 10 days of August was around $8 \mathrm{~mm}$, which comprises only $8 \%$ of the mean value. These meteorological conditions led to the high potential risks of forest and peat bog fires near Moscow. In order to characterize in complex the potential fire severity, Nesterov's classes of flammability $N$ were used. The $N$ was calculated from the accumulated flammability indices $I=\sum\left(t_{15} d\right)$, where $t_{15}$ is the air temperature at 15:00 LT, $d$ - dew point depression in the absence of daily precipitation higher than $3 \mathrm{~mm}$ (Nesterov et al., 1968). If precipitation is higher, $I$ is zeroised. Fire risks were classified with $N$ fire class values from 1 to 5 , where $N=3(1001<I<4000), N=4(4001<$ $I<10000), N=5(I>10001)$ relate to dangerous, highly dangerous and extremely dangerous fire conditions, respectively.

Table 1 contains the number of days with different classes $N$ in 2010 and their average values over the 1961-1990 period, which is classified as a WMO standard period. Usually, during July-August the classes with $N<=3$ comprise more than $85 \%$ (or 53 days), and only 3 days are recorded with $N=4$ and $N=5$. However, in 2010 the conditions with $N=4$ and $N=5$ were observed during 33 days and 
Table 1. Day number with different Nesterov's classes of flammability in typical conditions for the WMO standard period 19611990 and in fire conditions during July-August 2010 period. Total day number for July-August period is 62. Meteorological Observatory of Moscow State University.

\begin{tabular}{lrr}
\hline Classes (indices thresholds) & $1961-1990$ & 2010 \\
\hline$N=3,4,5(I>1000)$ & 17 & 42 \\
$N=4,5(I>4000)$ & 3 & 33 \\
$N=5(I>10000)$ & $<1$ & 17 \\
\hline
\end{tabular}

extremely dangerous fire situations $(N=5)$ during 17 days: from 25 July 2010 up to 10 August 2010. During this period especially favorable conditions for fire inflammation were observed.

We should also note that the drainage of large peat areas around Moscow in the 1930s and dense population near Moscow provided an additional potential for generating strong forest and peat fires in this region, which began from the middle of July 2010.

Figure 2 shows variation of Nesterov's flammability classes $N$ and level 2.0 aerosol optical thickness at $500 \mathrm{~nm}$ (AOT500) in Moscow during July-August period. One can see a permanent AOT500 increase during July with approximately dAOT500 $=0.03$ growth per day (correlation coefficient $R=0.76$ ) and unprecedented spikes on 6-8 August up to $\mathrm{AOT} 500=4.6$ on 7 August. However, after the precipitation occurred on 11 and 13 August, AOT500 dropped down to the values less than 1.5. Finally, after the change of the atmospheric circulation (see the examples of NASA/GSFC 7-day backward trajectories for different days in Fig. 3), AOT500 decreased to $0.05-0.07$ after 18 August. These small AOT500 values comprised only $20 \%$ of the August $10 \mathrm{yr}$ mean AOT500 $=0.35$ (Chubarova et al., 2011c). Overall, monthly mean AOT500 for August 2010 reached 1.1, which is an absolute maximum over the $10 \mathrm{yr}$ period of observations in Moscow.

There is a distinct correlation between the AOT in Moscow and Zvenigorod during the most severe fire period with correlation coefficient $R=0.86$ (Fig. 4). However, there are some noticeable differences in AOT for some days due to spatial heterogeneity of the "fire" cloud. In typical conditions the correlation between AOT values at these sites is usually higher $(R>0.9)$ (Chubarova et al., 2011a).

The absolute AOT500 maximum was observed both in Moscow and in Zvenigorod on 7 August 2010. Note that for this day, in Moscow (see Fig. 4) there was a significant difference (dAOT500 $=1.3$ ) between the daily average AOT500, evaluated with special processing (see the discussion in Sect. 2) and the values obtained with the standard algorithm. As it was mentioned earlier, the cause of this large bias is explained by removing from the standard dataset the cases with extremely high AOT, which has significant

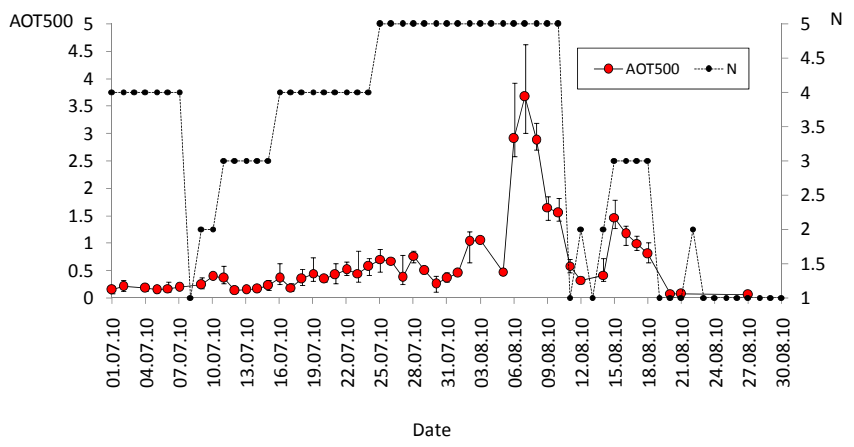

Fig. 2. Daily mean AOT500 (level 2) with error bar showing the variation range during the day (a) and Nesterov's classes of flammability $N$ (b). Meteorological Observatory of Moscow State University.

triplet variation. Figure 5a presents the diurnal variation of AOT during 7 August 2010 according to Moscow and Zvenigorod data. Moscow level 2.0 AOT500 reached 4.6. However, level 2.0 dataset provides only the morning data (see Fig. 5a). It is clearly seen that real AOT500 maximum obtained from special processing was observed later during daytime and reached 6.4 in Moscow and 5.9 in Zvenigorod. These AOT500 changes in Moscow are in a good agreement with diurnal variations of the solar irradiance losses $(L$, $\%$ ) observed at the Meteorological Observatory of Moscow State University (see Fig. 5a), which will be discussed in details later. One can also notice significant temporal variability in the AOT time series during 7 August in Moscow and Zvenigorod. The analysis of NASA/GSFC 7-day backward trajectories on 7 August shows the prevailing advection from southern regions and from the east at the height of $5 \mathrm{~km}$ (see Fig. 3). Since there were no noticeable fires between Moscow and Zvenigorod, we can attribute this difference to the AOT structure of the fire cloud, which had moved slowly from south-south-eastern direction and covered first Moscow and then Zvenigorod with approximately $3 \mathrm{~h}$ lag in time. MODIS picture also shows a strong heterogeneity of fire cloud (see Fig. 5b) and extremely high AOT550 over the Moscow region.

\subsection{Microphysical and optical aerosol characteristics during fires}

The advection of "fire" aerosol cloud significantly changed the properties of typical aerosol over the vast territory of Central Russia. In addition to extremely large aerosol optical thickness observed during this advection, one can see the changes in other aerosol characteristics. Figure 6 shows the mean volume aerosol size distribution $d V(r) / d \ln r\left(\mu \mathrm{m}^{3} / \mu \mathrm{m}^{2}\right)$ for the period with fire conditions in Moscow and volume aerosol size distribution for typical mean aerosol over the 2001-2010 period in the range of particle size $0.05 \mu \mathrm{m} \leq$ $r \leq 15 \mu \mathrm{m}$. Typical aerosol is characterized by the presence 

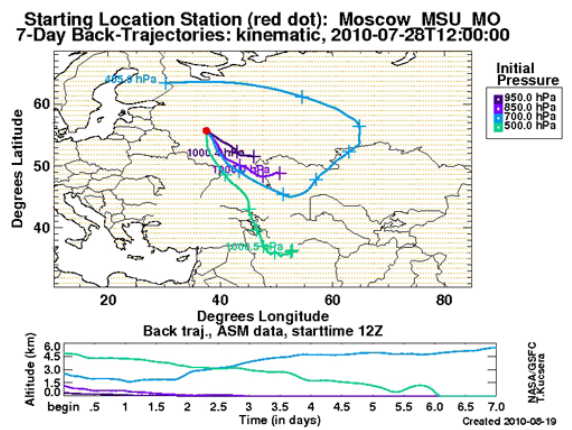

(a)
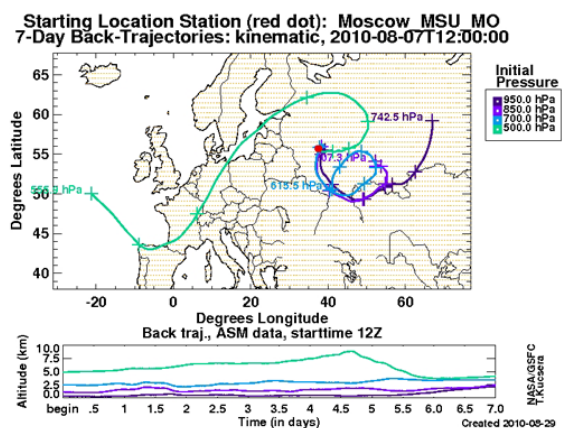

(b)

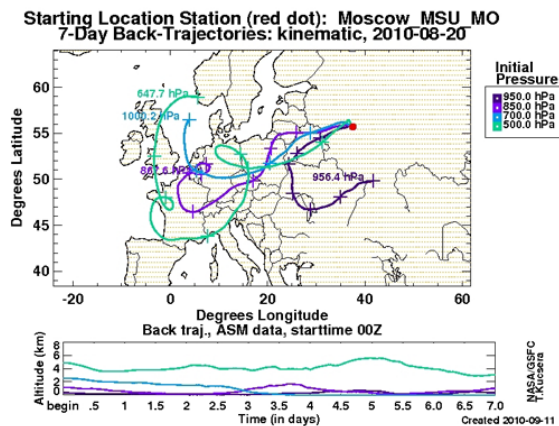

(c)

Fig. 3. NASA/GSFC 7-days backward trajectories for the day with typical synoptic situation in July (28 July) - (a), for the day with the strongest fire cloud over Moscow and Zvenigorod (7 August) - (b), and for the day after the fires (20 August) - (c).

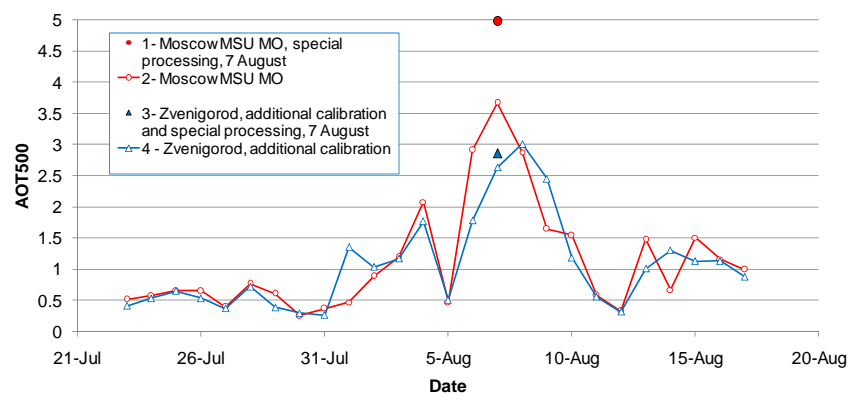

Fig. 4. Daily mean AOT500 time series in Moscow and Zvenigorod during the most intensive fire event from 23 July to $17 \mathrm{Au}-$ gust 2010. (1) Moscow MSU MO AOT500, special processing on 7 August (see the details in Sect. 2); (2) Moscow MSU MO AOT500, AERONET level 2; (3) Zvenigorod AOT500, special processing on 7 August and an application of additional calibration (see the details in Sect. 2); (4) Zvenigorod AOT500, an application of additional calibration and cloud-screening filter (Smirnov et al., 2000).

of both fine $(r<0.7 \mu \mathrm{m})$ and coarse $(r>0.7 \mu \mathrm{m})$ aerosol modes. This is in agreement with the urban aerosol type, which is characterized by some additional increase in coarse mode (Dubovik et al., 2002; Chubarova et al., 2011a). However, during the fire event one can see much more pronounced increase in fine aerosol mode and a shift in fine aerosol mode distribution towards larger radii. Figure 7 illustrates an approximately linear dependence of fine mode radii on AOT, while there are no noticeable changes for the coarse mode. In Moscow, typical conditions mean volume aerosol distribution of fine mode particles corresponds to the effective radius $r_{\text {eff-fine }}=0.15 \mu \mathrm{m}$, while in smoke conditions 2010, the effective radius of fine mode particles increased to $r_{\text {eff-fine }}=0.24 \mu \mathrm{m}$ at extremely high AOT. Usually, total column volume aerosol content (or "volume concentration" as it is denominated at the AERONET website) is characterized by $0.07 \mu \mathrm{m}^{3} \mu \mathrm{m}^{-2}$, with about $55 \%$ fine mode particles fraction in the total volume content. During the
2010 fire event, total column volume aerosol content was 4 times larger $\left(\sim 0.33 \mu \mathrm{m}^{3} \mu \mathrm{m}^{-2}\right)$ with much more pronounced prevalence $(\sim 70 \%)$ of fine mode aerosol content.

\subsection{Refractive indices}

The retrievals of refractive indices are the standard product of AERONET (Dubovik and King, 2000). Real and imaginary parts of refractive index (REFR and REFI, respectively) are the important optical characteristics of aerosol. Figure 8 shows REFR and REFI spectral dependences in typical and smoke aerosol conditions. We also added the measurements observed during 2002 fire event, when much more statistics were available. REFR values for typical aerosol relate to the non-hygroscopic type of aerosol particles (Dubovik et al., 2002). However, both REFR observed in 2002 and in 2010 during fire events were higher than the typical values (see Fig. 8 and Table 2). The highest values were recorded in 2010, possibly due to extremely high temperatures and small relative humidity of the atmosphere, which can lead to drying the aerosol particles. Relatively high REFR values of smoke aerosol in visible spectral region are in an agreement with the results obtained in other geographical regions with biomass burning aerosol (Dubovik et al., 2002). At the same time, the imaginary part of refractive index observed in 2010 is less than that in typical Moscow conditions and corresponds well to the results observed during 2002 fire event (see Table 2).

\subsection{Factor of asymmetry and single scattering albedo}

The important radiative characteristics of aerosol - an asymmetry factor of the aerosol phase function $(g)$ and aerosol single scattering albedo (SSA) - are also available from the AERONET inversion algorithm. While in fire conditions aerosol asymmetry factor of aerosol phase function is similar to that in typical situations (see Table 2), there are some differences in single scattering albedo values. Figure 9 shows SSA spectral dependence for different aerosol types, including typical Moscow aerosol and smoke aerosol observed in 


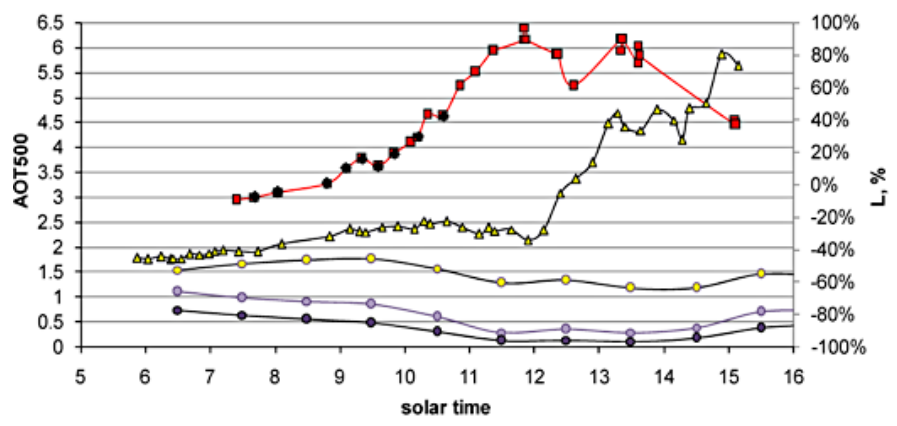

\begin{tabular}{|ll|}
$\rightarrow-$ Moscow AOT500 & $-\triangle-$ Zvenigorod AOT500 \\
- MoscowAOT500, level 2 & $\multimap-$ L, total shortwave irradiance \\
$\rightarrow-$ L, UV300-380nm & $-\circ$ L, EW Irradiance \\
\hline
\end{tabular}

a.

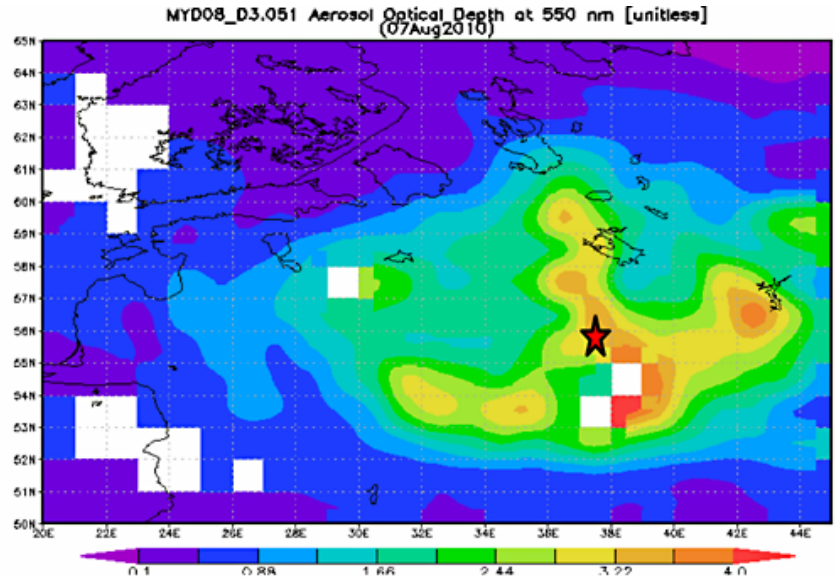

b.

Fig. 5. Temporal variations of AOT500 in Moscow and Zvenigorod during 7 August 2010, when the highest aerosol loading was observed (a); spatial aerosol variation according to MODIS AOT550 data over the Moscow region for the same day (b) (from http://disc.sci.gsfc.nasa.gov/ giovanni).

Table 2. Aerosol properties during fire events observed in 2002, 2010 and in typical August conditions over the period 2001-2009. Meteorological observatory of Moscow State University.

\begin{tabular}{|c|c|c|c|c|c|c|c|c|c|c|c|c|}
\hline \multirow[t]{2}{*}{ Statistics } & \multicolumn{3}{|c|}{$\begin{array}{l}\text { Real part of } \\
\text { refractive index, } \\
\text { REFR }(675 \mathrm{~nm})\end{array}$} & \multicolumn{3}{|c|}{$\begin{array}{l}\text { Imaginary part } \\
\text { of refractive index, } \\
\text { REFI }(675 \mathrm{~nm})\end{array}$} & \multicolumn{3}{|c|}{$\begin{array}{c}\text { Factor of } \\
\text { asymmetry } g \\
(675 \mathrm{~nm})\end{array}$} & \multicolumn{3}{|c|}{$\begin{array}{c}\text { Single scattering } \\
\text { albedo, SSA } \\
(675 \mathrm{~nm})\end{array}$} \\
\hline & $\begin{array}{r}\text { typical } \\
\text { conditions }\end{array}$ & $\begin{array}{r}\text { fire } \\
\text { conditions } \\
2010\end{array}$ & $\begin{array}{r}\text { fire } \\
\text { conditions } \\
2002\end{array}$ & $\begin{array}{r}\text { typical } \\
\text { conditions }\end{array}$ & $\begin{array}{r}\text { fire } \\
\text { conditions } \\
2010\end{array}$ & $\begin{array}{r}\text { fire } \\
\text { conditions } \\
2002\end{array}$ & $\begin{array}{r}\text { typical } \\
\text { conditions }\end{array}$ & $\begin{array}{r}\text { fire } \\
\text { conditions } \\
2010\end{array}$ & $\begin{array}{r}\text { fire } \\
\text { conditions } \\
2002\end{array}$ & $\begin{array}{r}\text { typical } \\
\text { conditions }\end{array}$ & $\begin{array}{r}\text { fire } \\
\text { conditions } \\
2010\end{array}$ & $\begin{array}{r}\text { fire } \\
\text { conditions } \\
2002\end{array}$ \\
\hline Average & 1.442 & 1.540 & 1.504 & 0.010 & 0.006 & 0.005 & 0.616 & 0.632 & 0.642 & 0.892 & 0.954 & 0.965 \\
\hline Median & 1.431 & 1.536 & 1.488 & 0.009 & 0.006 & 0.006 & 0.612 & 0.643 & 0.616 & 0.881 & 0.959 & 0.955 \\
\hline Max & 1.583 & 1.583 & 1.589 & 0.023 & 0.008 & 0.010 & 0.707 & 0.665 & 0.668 & 0.969 & 0.969 & 0.979 \\
\hline Min & 1.356 & 1.489 & 1.387 & 0.003 & 0.004 & 0.002 & 0.521 & 0.586 & 0.575 & 0.785 & 0.927 & 0.905 \\
\hline Sigma & 0.058 & 0.033 & 0.034 & 0.004 & 0.001 & 0.001 & 0.031 & 0.028 & 0.023 & 0.041 & 0.015 & 0.014 \\
\hline case number & 209 & 63 & 7 & 209 & 63 & 7 & 209 & 63 & 7 & 209 & 63 & 7 \\
\hline
\end{tabular}

Comments: additional filter AOT500 > 0.6 was applied to determine fire conditions in 2002 and 2010.

Moscow during the 2002 and 2010 fire events. One can also see there some literature data from Dubovik et al. (2002). In typical conditions in Moscow, mean SSA changes from 0.9 to 0.87 within the $440-1020 \mathrm{~nm}$ spectral interval. These values are in an agreement with the SSA values of the aerosol continental model (WMO, WCRP, 1987). However, in nonurban conditions SSA values can be somewhat higher but the difference is not statistically significant (Chubarova et al., 2011a). At the same time smoke aerosol SSA values in visible and near infrared region significantly differ from the values in typical conditions (see Fig. 9, Table 2). Similar smoke aerosol SSA values were observed during the 2002 and 2010 fire events. Single scattering albedo in these conditions is larger due to smaller imaginary part of refractive index and the prevalence of fine aerosol mode, and is also characterized by relatively weak spectral dependence. These SSA correspond well to the other SSA retrievals for smouldering smoke aerosol observed in forest fires conditions in Canada andBrasilia within the error of their estimating ( 0.03) (Dubovik et al., 2002; Eck et al., 2003).

\subsection{Radiative effects of aerosol}

\subsubsection{Solar irradiance loss at ground due to smoke aerosol in different spectral regions}

Solar irradiance underwent a significant attenuation in conditions with smoke aerosol. Figure 10 shows the dependence of the irradiance loss $(L, \%)$ in different spectral intervals as a function of AOT500 during the 2010 fire event. One can see a pronounced nonlinear character of the dependence and much noticeable attenuation of UV irradiance (especially in its UV-B range) compared with that for shortwave irradiance.

Maximum losses reached $64 \%$ for shortwave irradiance, $91 \%$ for UV radiation $300-380 \mathrm{~nm}$ and $97 \%$ for erythemally-weighted irradiance (EW irradiance) on $7 \mathrm{Au}-$ gust at solar elevation $h=47^{\circ}$ within 13:00-14:00 solar time (see Fig. 5a). These are the most severe radiative losses due to aerosol loading observed over the whole period of measurements at the MSU MO in cloudless conditions. One can see a pronounced spectral character of 


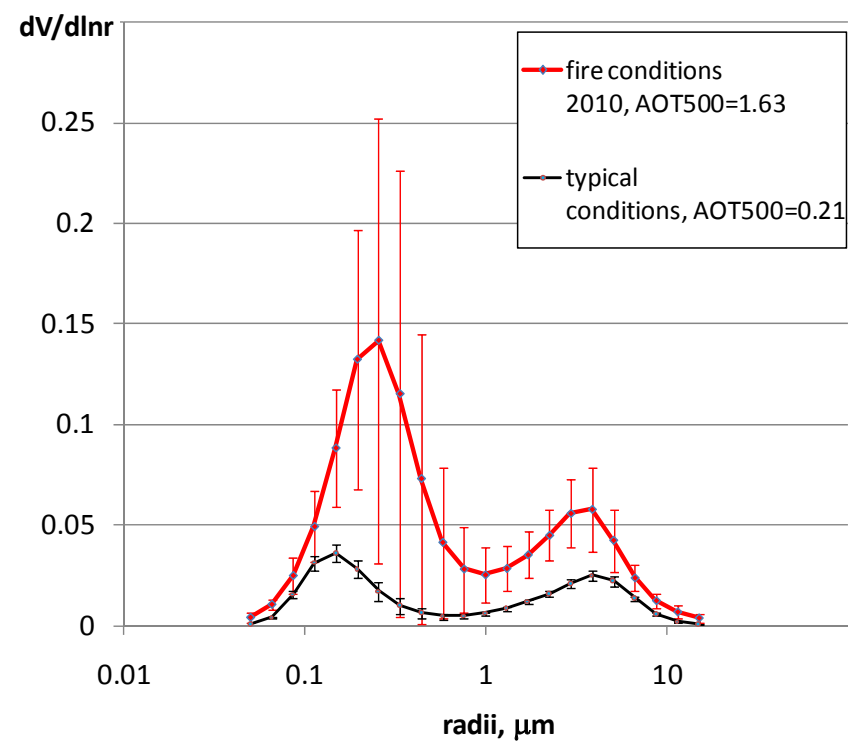

Fig. 6. Mean aerosol volume size distribution $d V(r) / d \ln r$ $\left(\mu \mathrm{m}^{3} / \mu \mathrm{m}^{2}\right)$ in fire conditions (red), August 2010, and typical August conditions (black) with the confidence intervals at $95 \%$. AOT500 values in the legend are the averages corresponding to the samples. Moscow.

solar irradiance attenuation that dramatically increases towards smaller wavelengths. In typical clear sky conditions, the portion of the UV300-380 $\mathrm{nm}$ in shortwave irradiance is about $4 \%$, but at extremely high AOT (7 August 2010) it falls down to $1 \%$. At the same time the fraction of EW irradiance in UV300-380 $\mathrm{nm}$ is also decreased from typically $0.35 \%$ to $0.2 \%$, when the most optically thick smoke aerosol cloud was observed. We should also note that similar higher attenuation in UV region compared with that for shortwave irradiance is described in Chubarova et al. (2009) for 2002 fire event.

In order to understand the reasons of significant radiation losses, the model RT simulations were fulfilled. As input parameters we used the AOT at $340 \mathrm{~nm}$ (AOT340) from AERONET dataset and the UV Angstrom parameter calculated from the aerosol optical thickness at 340 and $380 \mathrm{~nm}$. Note that the difference between AOT340 and AOT500 is always positive and varies from 0.2 up to 1.2. Unfortunately, SSA retrievals in UV spectrum (SSAUv) are not available in AERONET algorithm. In our previous approach, which has been applied to the data analysis of Moscow 2002 fire event, we used the approximate model fitting to evaluate the SSA values, which are necessary to apply in the model for obtaining the agreement with UV losses in smoke aerosol conditions. We also examined matching the measurements and model results for shortwave irradiance using the data of RT calculations available at the AERONET web page, which were fulfilled with the observed aerosol parameters. An additional $\mathrm{NO}_{2}$ absorption observed during the fire events was

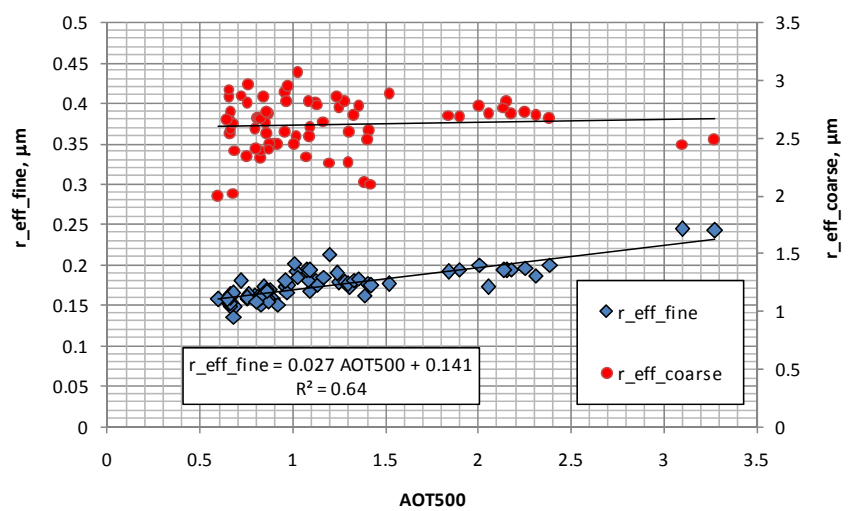

Fig. 7. Changes in effective radii of fine (left axis) and coarse (right axis) aerosol modes versus aerosol content (AOT500) during the fire conditions. The regression equation is given for fine mode particles.

also taken into account. This factor can be responsible for the extra 3-9\% loss of UV300-380 nm and EW irradiance.

The results of the comparisons are shown in Fig. 11. There is a perfect agreement between model and measured shortwave irradiance: there is no bias, standard deviation is about $3 \%$, and maximum difference does not exceed $10 \%$. Figure 11 also presents the comparisons made for UV spectrum. When calculating UV irradiance we used here the SSA at $441 \mathrm{~nm}$. One can see that the application of SSA from visible spectral range has led to the dramatic difference between UV measurements and modeling of about $50 \%$ at large AOT.

Using the approach described above for each case, we calculated the SSA $A_{U V}$ values which would give a perfect agreement with UV measurements. According to our estimations, the SSA UV should be significantly lower to match model irradiance with UV observations (see Fig. 11) both for UV300$380 \mathrm{~nm}$ and for EW irradiance, which has the maximum sensitivity in UV-B spectral region. Overall, for UV300-380 nm irradiance the SSA $\mathrm{UV}_{\mathrm{U}}$ should be around 0.9 , and it should be around 0.8 for EW irradiance. This is quite reasonable because the high concentration of organic compounds in smoke aerosol can dramatically increase the aerosol absorption coefficient in UV and especially in UV-B spectral region (Sviridenkov, 2008). At the same time we obtained quite pronounced SSA $\mathrm{SU}_{\mathrm{V}}$ decrease with the AOT500 increase for both UV300-380 nm and EW irradiance (see Fig. 11). The existing SSA $A_{U V}$ attenuation at very high AOT values can be explained by increasing the content of organic component with AOT growth during these aerosol spikes. However, further study is necessary to verify the possible uncertainty of the retrievals in the conditions with extremely high aerosol loading.

As a result, we can state that the dramatic UV irradiance loss compared with shortwave irradiance is explained by several factors: by higher AOT in UV from 0.2 up to 1.2 , by lower $\mathrm{SSA}_{\mathrm{UV}} \sim 0.8-0.9$, and by some additional effects of gas absorption (few percents). 


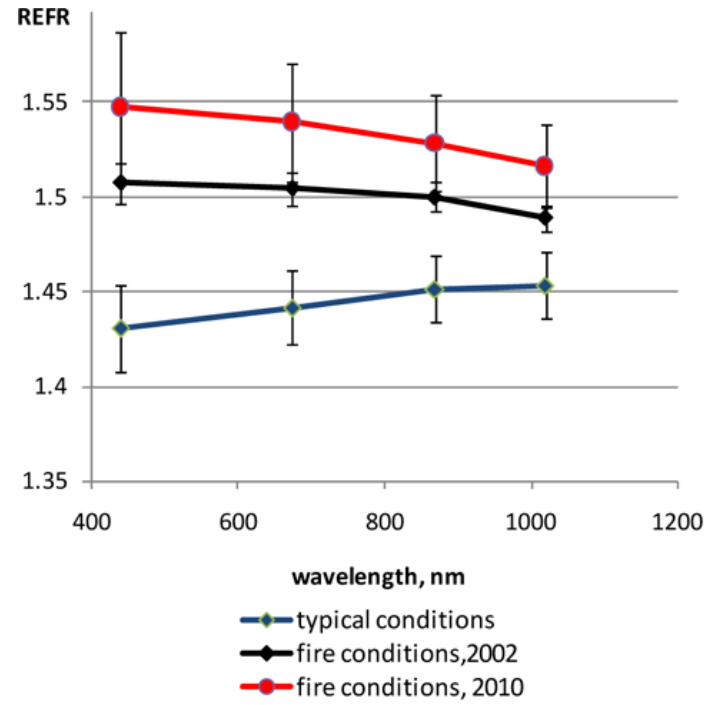

a.

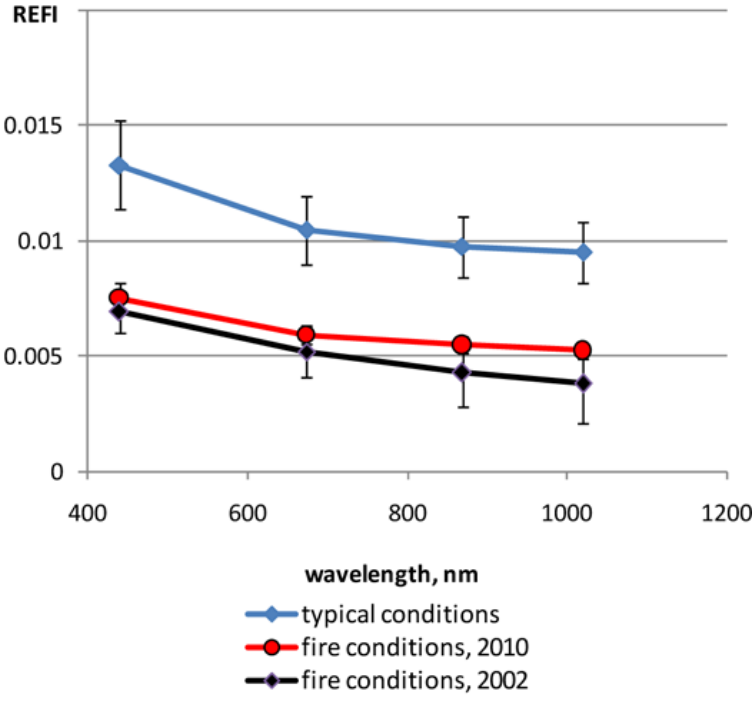

b.

Fig. 8. Spectral dependence of real REFR (a) and imaginary REFI (b) part of refractive index in typical conditions (blue color) without fires during 2001-2010 and during forest fires events $2002(n=63$, shown in black), and 2010 ( $n=7$, shown in red) with error bars at $95 \%$ confidence level.

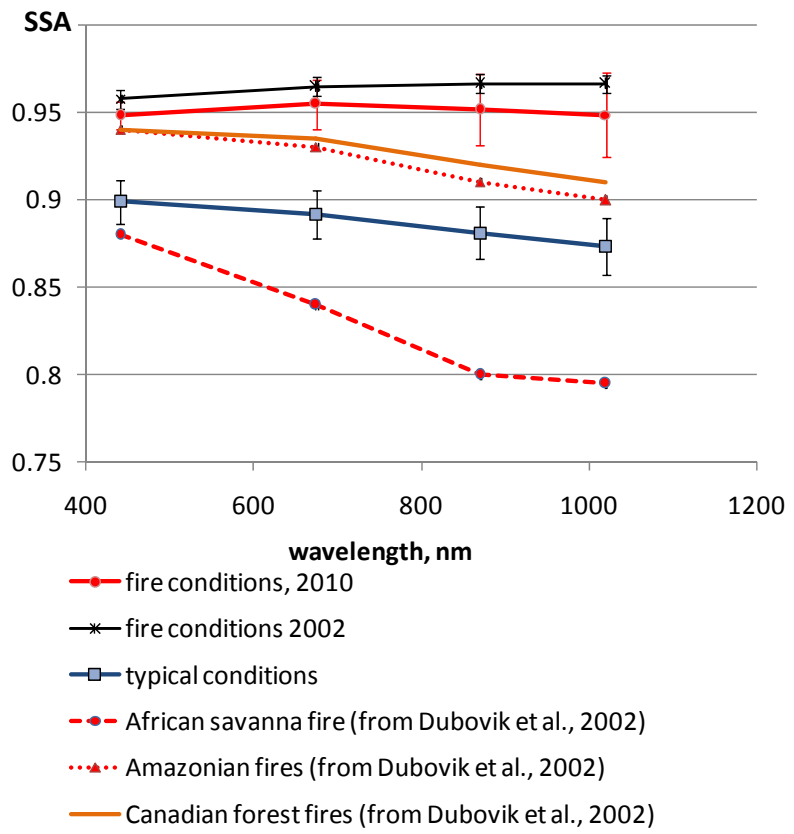

Fig. 9. Spectral dependence of aerosol single scattering albedo (SSA) for Moscow fire conditions in 2010, 2002, and typical conditions with confidence intervals at $95 \%$. In addition, the SSA values over other areas with biomass burning aerosol are shown according to Dubovik et al. (2002).

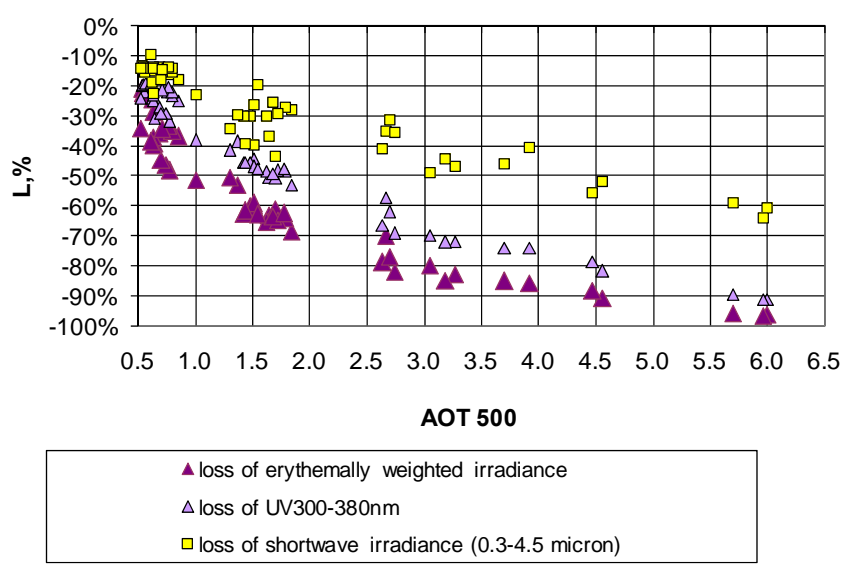

Fig. 10. The losses $(L, \%)$ of erythemally-weighted UV irradiance, UV irradiance 300-380 nm (UV300-380 nm), and shortwave irradiance $(0.3-4.5 \mu \mathrm{m})$ as a function of aerosol optical thickness at $500 \mathrm{~nm}$ (AOT500) during the fire event in 2010. Meteorological Observatory of Moscow State University.

\subsubsection{Radiative forcing effects at the top of the atmosphere}

The characteristic "aerosol radiative forcing effect (RFE) at the top of the atmosphere (TOA)" is widely used in calculating the impact of aerosol on climate. Since the standard AERONET radiation products include the RFE calculation (Garcia et al., 2008), we used this characteristic to estimate the influence of smoke aerosol and to compare these effects with the RFE for typical aerosol conditions. 


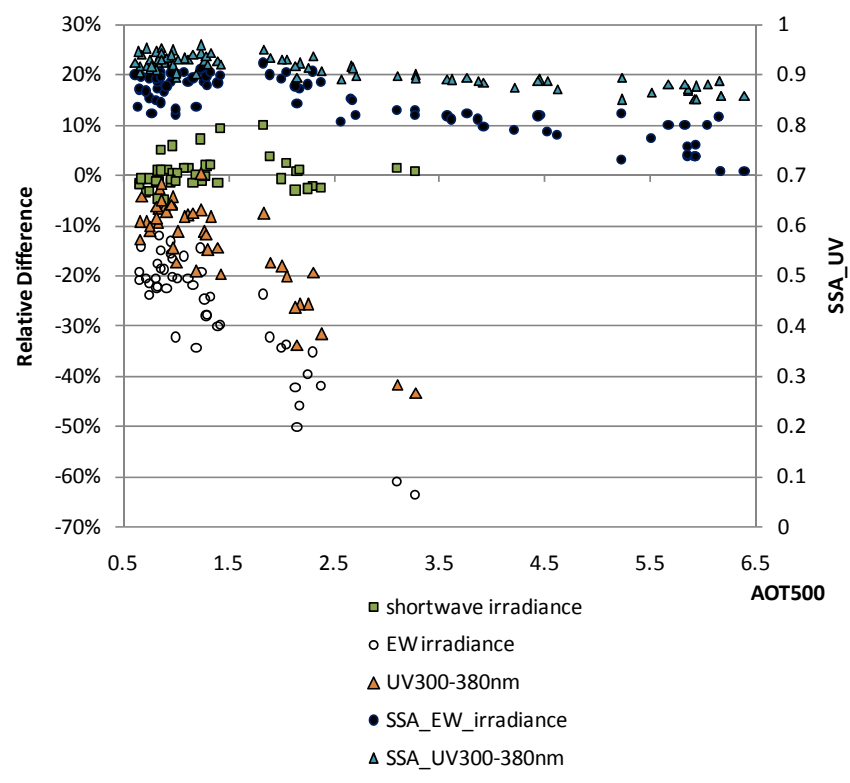

Fig. 11. Comparisons between measurements and modelling (Relative Difference $=$ Measurement/Modelling-1, \%) for shortwave irradiance, UV300-380 $\mathrm{nm}$ and EW irradiance (left axis) and the retrievals of SSA for EW irradiance and UV300-380 nm (right axis). See the details in the text.

The AERONET aerosol radiative forcing (or, more accurate, radiative forcing effect, RFE) is defined as the difference between the global solar irradiance with and without aerosol at the top and at the bottom of the atmosphere.

$\mathrm{RFE}_{\mathrm{TOA}}=-\left(F \uparrow_{\mathrm{aTOA}}-F \uparrow_{\mathrm{oTOA}}\right)$

$\mathrm{RFE}_{\mathrm{BOA}}=\left(F \downarrow_{\mathrm{aBOA}}-F_{\downarrow \mathrm{OBOA}}\right)$,

where $F_{\mathrm{a}}$ and $F_{\mathrm{o}}$ are the broadband fluxes at the top (TOA) and at the bottom (BOA) of the atmosphere with and without aerosols, respectively. However, when we speak about the RFE difference at the top of the atmosphere, the resulting value will be the same as if considering the net fluxes, which are usually used in the RFE analysis (see, for example, Yu et al., 2006; IPCC, 2007).

Since the radiative aerosol properties were quite similar during the fires 2002 and 2010, we combined all the data in order to obtain the dependence of RFE versus AOT500. In addition, we obtained the average dependence of RFE versus AOT500 for typical clear sky July-August conditions during 2001-2009. For these two groups we combined all available RFE retrievals within the wide range of aerosol characteristics and solar zenith angles in $50-75^{\circ}$ range. Note that there is only a slight RFE dependence on solar zenith angle within few $\mathrm{Wm}^{-2}$ (Derimian et al., 2008, Fig. 9b; Haywood and Shine, 1997) at relatively low surface albedo typical for summer conditions. However, using the whole statistics we take into account for these slight changes when characterizing the climatic effect of aerosol.

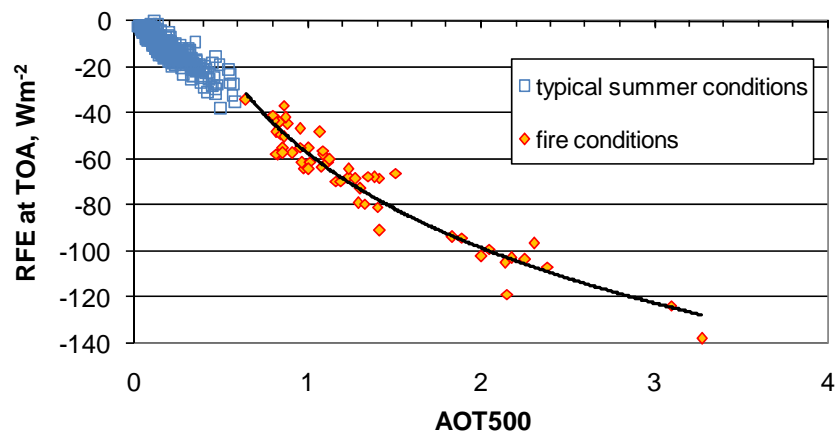

Fig. 12. Radiative forcing effects (RFE) at the top of the atmosphere (TOA) as a function of AOT500 in typical conditions (for JulyAugust period) and during the fire events 2002 and 2010.

The average RFE for typical conditions can be approximated by linear regression as a function of AOT (Fig. 12). However, for fire conditions we need to take into account a non-linear dependence mainly due to much larger range of AOT and low smoke aerosol absorption in visible spectral range.

For typical aerosol the dependence of RFE at the TOA can be approximated by the following equation:

$\mathrm{RFE}_{\text {typical }}=-58.3 \mathrm{AOT} 500, R^{2}=0.8$.

For smoke aerosol the equation is the following:

$\mathrm{RFE}_{\text {fires }}=-59.26 \ln ($ AOT500 $)-56.951$,

at $\mathrm{AOT} 500>0.6, R^{2}=0.92$.

The larger RFE variations in typical conditions (see lower $R^{2}$ ) are observed due to significant changes in single scattering albedo within $\mathrm{SSA}_{675}=0.78-0.98$ in the sample.

The application of the Eqs. (3) and (4) to various sets of AOT provides the assessment of radiative effects of aerosol on climate system. Table 3 contains the mean and maximum RFE values for fire and typical aerosol conditions. One can see that the maximum instant effect can reach $-167 \mathrm{Wm}^{-2}$, which can lead to extremely intensive cooling of the atmosphere, while even monthly mean effect $\left(-65 \mathrm{Wm}^{-2}\right)$ calculated for August 2010 is more than 3 times higher than the radiative cooling effects of typical aerosol.

\section{Discussion}

Summer 2010 in Central Russia was characterized by unprecedented high temperatures and by the absence of precipitation. This was expressed in large number of days (17 days) with the extremely dangerous Nesterov's flammability classes $N=5$, during which the most intensive fires were generated over Central Russia. For comparison, in 2002 the number of days with $N=5$ comprised 12 , while in 1972, when the first intensive wildfires were observed near 
Table 3. Instant and climatological aerosol radiative forcing effects (RFE) at the TOA. Summer conditions. Calculations were made using the regression dependences (3) and (4) (see the text and Fig. 12).

\begin{tabular}{lrrrr}
\hline & $\begin{array}{r}\text { Instant values } \\
\text { for maximum } \\
\text { AOT at level 1 }\end{array}$ & $\begin{array}{r}\text { Instant values } \\
\text { for maximum } \\
\text { AOT at level 2 }\end{array}$ & $\begin{array}{r}\text { Mean values } \\
\text { for }\end{array}$ & $\begin{array}{r}\text { Mean typical } \\
\text { conditions, over } \\
\text { 2001-2010, August }\end{array}$ \\
\hline AOT500 & 6.4 & 4.6 & 1.14 & 0.35 \\
RFE, Wm ${ }^{-2}$ & -167 & -147 & -65 & -20 \\
\hline
\end{tabular}

the Moscow region, there was only 5 days with $N=5$. This matches well with the AOT level as well as with the level of radiative losses in 2010, 2002 and 1972 (Chubarova et al., 2011b). The largest AOT values and radiative losses were observed in 2010, the smallest ones in 1972.

The analysis of aerosol properties during the extremely intensive wildfires over Central Russia in 2010 has revealed some interesting features. Microphysical properties of smoke aerosol have a noticeable increase of fine mode fraction: it comprised about $70 \%$ of total volume content in 2010 and $73 \%$ during the fires in 2002 compared with $55 \%$ in typical conditions.

These results are in an agreement with the data obtained by Dubovik et al. (2002) and Eck et al. (2003) for biomass burning aerosol. There is also a pronounced shift in fine aerosol mode distribution towards larger radii from $r_{\text {eff fine }}=0.15 \mu \mathrm{m}$ in typical conditions to the value of $0.24 \mu \mathrm{m}$ at extremely high AOT during 2010 fire event.

Real part of the refractive index $(\operatorname{REFR}=1.54)$ is higher than that in typical conditions $($ REFR $=1.44)$, while the imaginary part of refractive index is much lower $(\mathrm{REFI}=0.006$ compared with $\mathrm{REFI}=0.010)$. The changes in size distribution and imaginary part of refractive index significantly increased single scattering albedo in visible region $(\mathrm{SSA}=0.95)$ compared with $\mathrm{SSA}=0.89$ in typical conditions. On the whole, the optical properties of smoke aerosol observed in 2010 are in a good agreement with those observed during 2002 fire event. However, the REFR is somewhat higher, possibly due to extremely high temperatures, which can lead to additional drying the aerosol particles.

Aerosol optical thickness at $500 \mathrm{~nm}$ reached its absolute maximum on 7 August with $\mathrm{AOT}=6.4$ in Moscow and $\mathrm{AOT}=5.9$ in Zvenigorod. This is approximately 2 times larger than the previous maximum AOT500 3 observed during the 2002 fire event (Chubarova et al., 2009). Note that these AOT maxima in 2010 were recorded simultaneously with the significant loss of solar irradiance and the unprecedented low visibility of about 100 meters. In 2002, the lowest visibility observed during the fire event was about $500 \mathrm{~m}$.

The irradiance losses also show some peculiar features. The most pronounced losses of solar irradiance were observed on 7 August between 11:00 and 14:00 solar time at high solar elevations $h$ and extremely high AOT500 $\sim 6$. The maximum losses of solar irradiance in all spectral intervals were observed after the solar noon at $h=47^{\circ}$ when EW irradiance was attenuated by $97 \%$, UV300-380 by $91 \%$ and shortwave irradiance by $64 \%$. Note that this is the most severe attenuation of solar irradiance observed in clear sky conditions for the whole period of observations. The largest attenuation during the 2002 fire event reached $75 \%$ for EW irradiance, $62 \%$ for UV300-380 and 32\% for shortwave irradiance (Chubarova et al., 2009).

Model simulations of shortwave irradiance (the AERONET RT algorithm) with exact aerosol input parameters have revealed an excellent agreement with measured values. However, these values cannot be used for UV irradiance modeling since in this case the discrepancy between model and measured values can reach more than $50 \%$. The $\mathrm{SSA}_{\mathrm{UV}}$ values are significantly lower than $\mathrm{SSA} \sim 0.95-0.96$ in visible spectral region (see Table 2 ).

According to our estimates, the average SSA for UV300$380 \mathrm{~nm}$ is about 0.9 and for EW irradiance it is about 0.8 , with a noticeable tendency to decreasing with AOT increase. At the same time, these SSAUV values are within the range of SSA obtained in UV-B spectral region in other geographical regions (Bais et al., 2007). We should note that according to our previous calculations (Chubarova et al., 2009), the best agreement between model and experimental UV data (and UV losses) in 2002 fire event was also observed after the application of $\mathrm{SSA}_{\mathrm{UV}}=0.9$ for AOT500 not exceeding 3 .

Overall, model calculations indicated the main reasons of the dramatic UV irradiance loss: higher AOT in UV compared with AOT in visible spectral region and lower SSA $_{U V}: \mathrm{SSA}_{\mathrm{UV}} \sim 0.8$ for $\mathrm{EW}$ irradiance, and $\mathrm{SSA}_{\mathrm{UV}} \sim 0.9$ for UV300-380 nm irradiance with the tendency of SSAUV decreasing with AOT growth.

In addition, radiative forcing effects of fire smoke aerosol at the top of the atmosphere were examined and compared with those in typical conditions. We obtained simple RFE approximations as a function of AOT500 for typical and smoke aerosols according to long-term AERONET measurements over Moscow. By using these equations, the assessments of RFE with different temporal averaging (instant and climatological) were obtained. The results for smoke aerosol were compared with the climatic value for typical non-smoke conditions. For typical August conditions (AOT500 =0.35), the computed RFE comprise about $-20 \mathrm{Wm}^{-2}$. This value is somewhat higher than the results obtained in (Yu et al., 2006) 
for summer conditions over this area $\left(-11.1 \mathrm{Wm}^{-2}\right)$. However, MODIS AOT retrievals used for this estimate are much lower (AOT550 0.2). After AOT correction, RFE values are in an agreement within $10 \%$.

In smoky conditions the maximum instant RFE at the TOA reached $-167 \mathrm{Wm}^{-2}$ at maximum $\mathrm{AOT} 500=6.4$, which should lead to intensive cooling of the atmosphere. In 2002, the maximum instant radiative forcing effect was much lower $\left(\mathrm{RFE} \sim-120 \mathrm{Wm}^{-2}\right.$ ) due to smaller AOT500 not exceeding 3. Even monthly mean RFE effect $\left(-65 \mathrm{Wm}^{-2}\right)$ estimated for August 2010 was more than 3 times higher than the typical radiative cooling of non-smoke aerosol.

\section{Conclusions}

The unprecedented intensive wildfires in 2010 created specific aerosol conditions with extremely high aerosol loading of the atmosphere reaching AOT500 $=6.4$ in Moscow, and 5.9 in Zvenigorod. They significantly exceeded the previous absolute AOT500 maximum, which was observed during the fire events in 2002 (AOT500 3).

There were some changes in optical properties of aerosol in smoke conditions with the increase in real part of refractive indices $(\mathrm{REFR}=1.54$ against $\mathrm{REFR}=1.44)$ and the decrease in imaginary part (REFI $=0.006$ against REFI $=0.010$ ).

Distinct loss of solar irradiance with non linear dependence on AOT500 was obtained with maxima reaching $64 \%$ for shortwave irradiance, $91 \%$ for UV radiation $300-380 \mathrm{~nm}$ and $97 \%$ for erythemally-weighted irradiance at solar elevation $47^{\circ}$. These are the highest radiative losses due to aerosol observed in Moscow for the whole period of observations. The stronger attenuation in UV region compared with shortwave irradiance is explained mainly by higher AOT in UV region and smaller SSA $\mathrm{SU}_{\mathrm{UV}}$, especially in UV-B part of spectrum.

The assessments of radiative forcing effect (RFE) at the TOA indicated a significant cooling of the atmosphere: RFE reached $-167 \mathrm{Wm}^{-2}$ at AOT500 $=6.4$. The climatological RFE value for August 2010 was about $-65 \mathrm{Wm}^{-2}$ compared with $-20 \mathrm{Wm}^{-2}$ for monthly mean AOT over $10 \mathrm{yr}$ of measurements.

Acknowledgements. The work was partially supported by the Ministry of Education and Science of the Russian Federation (contract \# no. 02.740.11.0676) and by RFBR grants \#10-05-01019, \#09-05-00582.

Edited by: G. de Leeuw

\section{References}

Bais, A. F., Lubin, D., Arola, A., Bernhard, G., Blumthaler, M., Chubarova, N., Erlick, C., Gies, H. P., Krotkov, N., Mayer, B., McKenzie, R. L., Piacentini, R., Seckmeyer, G., and Slusser, J. R.: Surface Ultraviolet Radiation: Past, Present and Future, Chapter 7 in Scientific Assessment of Ozone Depletion, World Meteorological Organization Global Ozone Research and Monitoring Project, Report No. 50, Geneva, 2007.

Chubarova, N. Y.: UV variability in Moscow according to long-term UV measurements and reconstruction model, Atmos. Chem. Phys., 8, 3025-3031, doi:10.5194/acp-8-3025-2008, 2008.

Chubarova, N. Y. and Nezval', Ye. I.: Thirty year variability of UV irradiance in Moscow, J. Geophys. Res., 105, 12529-12539, 2000.

Chubarova, N. Y., Prilepsky, N. G., Rublev, A. N., and Riebau, A. R.: A Mega-Fire Event in Central Russia: Fire Weather, Radiative, and Optical Properties of the Atmosphere, and Consequences for Subboreal Forest Plants, in: Developments in Environmental Science, edited by: Bytnerowicz, A., Arbaugh, M., Riebau, A., and Andersen, C., Elsevier B.V., Volume 8, 249-267, 2009.

Chubarova, N. Y., Sviridenkov, M. A., Smirnov, A., and Holben, B. N.: Assessments of urban aerosol pollution in Moscow and its radiative effects, Atmos. Meas. Tech., 4, 367-378, doi:10.5194/amt-4-367-2011, 2011a.

Chubarova, N. Y., Gorbarenko, E. V., Nezval', E. I., and Shilovtseva, O. A.: Aerosol and radiative characteristics of the atmosphere during the forest and peat bog fires in 1972, 2002 and 2010 in Moscow suburbs according to the data of Meteorological Observatory of MSU, J. Atmos. Ocean. Phys., 47, 729-738, 2011 b.

Chubarova, N. Y., Smirnov, A., and Holben, B. N.: Aerosol properties in Moscow according to 10 years of AERONET measurements at the Meteorological Observatory of Moscow State University, Geography, Environment, Sustainability, 4, 19-32, 2011c.

Derimian, Y., Leon, J.-F., Dubovik, O., Chiapello, I., Tanré, D., Sinyuk, A., Auriol, F., Podvin, T., Brogniez, G., and Holben, B. N.: Radiative properties of aerosol mixture observed during the dry season 2006 over M'Bour, Senegal (African Monsoon Multidisciplinary Analysis campaign), J. Geophys. Res., 113, D00C09, doi:10.1029/2008JD009904, 2008.

Dubovik, O. and King, M. D.: A flexible inversion algorithm for retrieval of aerosol optical properties from Sun and sky radiance measurements, J. Geophys. Res., 105, 20673-20696, 2000.

Dubovik, O., Holben, B. N., Eck, T. F., Smirnov, A., Kaufman, Y. J., King, M. D., Tanre, D., and Slutsker I.: Variability of absorption and optical properties of key aerosol types observed in worldwide locations, J. Atmos. Sci., 59, 590-608, 2002.

Eck, T. F., Holben, B. N., Reid, J. S., Dubovik, O., Smirnov, A., O’Neill, N. T., Slutsker, I., and Kinne, S.: Wavelength dependence of the optical depth of biomass burning, urban, and desert dust aerosols, J. Geophys. Res., 104, 31333-31349, 1999.

Eck, T. F., Holben, B. N., Reid, J. S., O’Neill, N. T., Schafer, J. S., Dubovik, O., Smirnov, A., Yamasoe, M. A., and Artaxo, P.: High aerosol optical depth biomass burning events: A comparison of optical properties for different source regions, Geophys. Res. Lett., 30, 2035, doi:10.1029/2003GL017861, 2003. 
Garcia, O. E., Diaz, A. M., Exposito, F. J., Diaz, J. P., Dubovik, O., Dubuisson, P., Roger, J.-C., Eck, T. F., Sinyuk, A., Derimian, Y., Dutton, E. G., Schafer, J. S., and Holben, B. N.: Validation of AERONET estimates of atmospheric solar fluxes and aerosol radiative forcing by ground-based broadband measurements, J. Geophys. Res., 113, D21207, doi:10.1029/2008JD010211, 2008.

Gorchakov, G. I., Anikin, P. P., Volokh, A. A., Emilenko, A. S., Isakov, A. A., Kopeikin, V. M., Ponomareva, T. Ya., Semutnikova, E. G., Sviridenkov, M. A., and Shukurov, K. A.: Studies of the Smoky Atmosphere Composition over Moscow during Peatbog Fires in the Summer-Fall Season of 2002, Izvestiya, Atmos. Ocean. Phys., 40, 323-336, 2004.

Haywood, J. M. and Shine, K. P.: Multi-spectral calculations of the direct radiative forcing of tropospheric sulphate and soot aerosols using a column model, Q. J. R. Meteorol. Soc., 123, 1907-1930, 1997.

Holben, B. N., Eck, T. F., Slutsker, I., Tanré, D., Buis, J. P., Setzer, A., Vermote, E., Reagan, J. A., Kaufman, Y. J., Nakajima, T., Lavenu, F., Jankowiak, I., and Smirnov, A.: AERONET-A federated instrument network and data archive for aerosol characterization, Remote Sens. Environ., 66, 1-16, 1998.

Holben, B. N., Tanre, D., Smirnov, A., Eck, T. F., Slutsker, I., Abuhassan, N., Newcomb, W. W., Schafer, J., Chatenet, B., Lavenue, F., Kaufman, Y. J., Vande Castle, J., Setzer, A., Markham, B., Clark, D., Frouin, R., Halthore, R., Karnieli, A., O’Neill, N. T., Pietras, C., Pinker, R. T., Voss, K., and Zibordi, G.: An emerging ground-based aerosol climatology: Aerosol Optical Depth from AERONET, J. Geophys. Res., 106, 12067-12097, 2001.

Holben, B. N., Eck, T., Slutsker, I., Smirnov, A., Sinyuk, A., Schafer, J., Giles, D., and Dubovik, O.: AERONET Version 2.0 quality assurance criteria, in: Remote Sensing of the Atmosphere and Clouds, edited by: Tsay, S.-C., Nakajima, T., Singh, R. P., and Sridharan, R., Proc. of SPIE, Goa, India, 13-17 November, 6408, 2006.

IPCC: Climate Change 2007, The Physical Science Basis, Contribution of Working Group I to the Fourth Assessment Report of the Intergovernmental Panel on Climate Change, edited by: Solomon, S., Qin, D., Manning, M., Chen, Z., Marquis, M., Averyt, K. B., Tignor, M., and Miller, H. L., Cambridge University Press, Cambridge, United Kingdom and New York, NY, USA, 2007

Korotaev, G. K., Sakerin, S. M., Ignatov, A. M., Stowe, L. L., and McClain, E. P.: Sun-photometer observations of aerosol optical thickness over the North-Atlantic from a Soviet research vessel for validation of satellite measurements, J. Atmos. Ocean. Tech., 10, 725-735, 1993.
Madronich, S. and Flocke, S.: The role of solar radiation in atmospheric chemistry, in: Handbook of environmental chemistry, Springer-Verlag, Heidelberg, 1-26, 1998.

Materials of All-Russian conference on the State of air basin of Moscow during the extreme weather conditions of summer 2010, Moscow, 25th November 2010, 50 pp., available at: http://ifaran. ru/science/seminars/Summer2010.html, 2010.

Nesterov, V. G., Gritsenko, M. V., and Shabunina, T. A.: Use of dew point temperature in the calculation of forest flammability, Meteorol. Hydrol., 4, 102-104, 1968.

Nezval', Ye. I. and Chubarova, N. Ye.: An applicability of the UVA1 YES to the continuation of long-term monitoring of UV irradiance 300-380nm in Moscow, in: Proceeding of the UV Conference "One Century of UV Radiation Research" 18-20 September 2007, Davos, Switzerland, edited by: Grobner, J., Davos, Switzerland, 51-52, 2007.

Seckmeyer, G., Bais, A., Bernhard, G., Blumthaler, M., Booth, C. R., Lantz, K., and McKenzie, R. L.: Instruments to measure solar ultraviolet irradiance, Part 2: Broadband instruments measuring erythemally weighted solar irradiance, WMO, Global Atmospheric Watch No. WMO TD, 1289, 51 pp., 2006.

Smirnov, A., Holben, B. N., Eck, T. F., Dubovik, O., and Slutsker, I.: Cloud-screening and quality control algorithms for the AERONET database, Remote Sens. Environ., 73, 337-349, 2000.

Sviridenkov, M. A.: Retrieving the single scattering albedo of smoke aerosols in UV from scattering and extinction measurements, European Aerosol Conference, Thessalonica, Greece, Abstracts, T06A112O, 2008.

Tarasova, T. A., Gorchakova, I. A., Sviridenkov, M. A., Anikin, P. P., and Romashova, E .V.: Estimation of the Radiative Forcing of Smoke Aerosol from Radiation Measurements at the Zvenigorod Scientific Station in the Summer of 2002, Izvestiya, Atmos. Ocean. Phys., 40, 454-463, 2004.

Uliumdzhieva, N., Chubarova, N., and Smirnov, A.: Aerosol characteristics of the atmosphere over Moscow from Cimel sun photometer data, Meteorol. Hydrol., 1, 48-57, 2005.

WMO, WCRP: A preliminary cloudless standard atmosphere for radiation computations, WCP-112, WMO/TD-24, World Clim. Res. Programme, Int. Assoc. for Meteorol. and Atmos. Phys., Geneva, 53 pp., 1987.

Yu, H., Kaufman, Y. J., Chin, M., Feingold, G., Remer, L. A., Anderson, T. L., Balkanski, Y., Bellouin, N., Boucher, O., Christopher, S., DeCola, P., Kahn, R., Koch, D., Loeb, N., Reddy, M. S., Schulz, M., Takemura, T., and Zhou, M.: A review of measurement-based assessments of the aerosol direct radiative effect and forcing, Atmos. Chem. Phys., 6, 613-666, doi:10.5194/acp-6-613-2006, 2006. 